\title{
Effects of lifelong intervention with an oligofructose-enriched inulin in rats on general health and lifespan
}

\author{
Pascale Rozan ${ }^{1}$, Amine Nejdi ${ }^{1}$, Sophie Hidalgo ${ }^{1}$, Jean-François Bisson ${ }^{1}$, Didier Desor ${ }^{2}$ \\ and Michäl Messaoudi ${ }^{1}$ \\ ${ }^{1}$ ETAP - Applied Ethology, 13 rue du Bois de la Champelle, F-54500 Vandoeuvre-lès-Nancy, France \\ ${ }^{2}$ Laboratoire de Neurosciences Comportementales, Université Henri Poincaré Nancy I, F-54500 Vandoeuvre-lès-Nancy, France \\ (Received 12 October 2007 - Revised 13 February 2008 - Accepted 19 February 2008 - First published online 11 April 2008)
}

Ageing is associated with changes in physiology and morphology; nutritional strategies to decrease morbidity and to prolong life are of high interest. The aim of the study was to investigate the effects of lifelong supplementation with an oligofructose-enriched inulin on morphological and biological markers and lifespan in male and female rats. Male and female rats, age 3 months, were randomised into two groups to receive either a diet with $10 \%$ of an oligofructose-enriched inulin (Synergy1) or a standard diet (control) for 27 months. The rats were weighed every 2 weeks and their food intake was evaluated on four successive days every 4-6 weeks. Samples were taken at 12, 18 and 24 months of age. During the whole intervention period, male rats receiving Synergy1 (SYN1-M) displayed lower body weight, cholesterol and plasma triacylglycerolaemia compared with the controls (Cont-M). The survival rate at 24 months of age of SYN1-M rats was $35.3 \%$ greater than that of Cont-M rats. In female rats, the Synergy 1 supplementation (SYN1-F) group also reduced body weight, cholesterol and triacylglycerolaemia levels, but results were less consistent over the experiment. The survival rate at 24 months of age in SYN1-F rats was $33.3 \%$ greater compared with that of the control (Cont-F) group. To conclude, lifelong intervention with Synergy1 improved biological markers during ageing and survival rate (lifespan) of rats.

Oligofructose-enriched inulin: Rats: Ageing: Biological markers

Inulin-type fructans are naturally occurring oligosaccharides found in many plants, such as onion, garlic, leek, artichoke, asparagus and chicory (Cichorium intybus) ${ }^{(1,2)}$. Inulin has a degree of polymerisation from 2 to $60+$, whereas oligofructose is produced by partial enzymic hydrolysis of the inulin chains and has a degree of polymerisation 3 to 8 . Inulintype fructans are built up of fructose monomers linked by $\beta-2-1$ bonds, making these compounds indigestible in the upper gastrointestinal tract ${ }^{(3)}$. Consequently, inulin and oligofructose enter the lower part of the intestine intact, where they are selectively fermented by the endogenous bacterial flora to SCFA, lactic acid and gases. Selective fermentation by the bacterial flora is a prerequisite for being a prebiotic. Prebiotics are non-digestible food ingredients that improve host health by selectively stimulating the growth and/or activity of one or a limited number of bacteria in the colon ${ }^{(4)}$. Numerous studies in human subjects have demonstrated that inulin and oligofructose intake increases the numbers of bifidobacteria and lactobacilli in the large intestine, and that these bacteria are associated with health ${ }^{(4-6)}$. Such associated health benefits upon inulin and oligofructose intake are an improvement in mineral absorption and bone mineralisation ${ }^{(7-11)}$, modulation of lipid metabolism ${ }^{(12-16)}$, immune-modulating activity ${ }^{(17)}$ and a reduction in cancer risk, mainly of the colon ${ }^{(18-20)}$.
The aim of the present study was to investigate the effects of lifelong intervention with an oligofructose-enriched inulin (10\% of Synergy 1$)$ in male and female rats on the ageing process and lifespan. Biological measures were performed every 6 months. To our knowledge, the present study is the first to report the effects of lifelong supplementation with an inulintype fructan.

\section{Materials and methods}

Animals

The study was carried out using sixty male and sixty female Sprague-Dawley rats (Charles River Laboratories, 69 St-Germain sur l'Arbresle, France), weighing 250-275 g (3 months old) at their arrival at ETAP Research Centre. Nine rats per group were used for anatomopathological analyses (three at 12, 18 and 24 months) and twelve other rats for biological sampling. At the end of the experiment, most of the rats had died, so the number of rats was less than twelve per group.

\section{Diets}

Standard food pellets (energy value $12.30 \mathrm{~kJ} / \mathrm{g}$ ) (M20 food pellets; Dietex, 95 Saint Gratien, France) were used to feed 
the rats. This diet contained $3.2 \%$ fat, $18.0 \%$ protein, $3.9 \%$ fibre, $57.5 \%$ total carbohydrates, $6.8 \%$ ash and $10.0 \%$ moisture. To prepare the test diet (energy value $12.01 \mathrm{~kJ} / \mathrm{g}$ ), $10 \%$ of an oligofructose-enriched inulin (Orafti ${ }^{\mathrm{TM}}$ Synergy 1 ; BENEO-Orafti N.V., Tienen, Belgium) was incorporated into the M20 pellets. Synergy1 is obtained from chicory root and is a selected combination of $90-94 \%$ of long inulin chains and shorter oligofructose chains $(1: 1)$ and $6-10 \%$ of mono- and disaccharides (glucose, fructose and sucrose). Diets were administered to rats from the age of 3 months and for the whole experiment.

\section{Housing conditions}

On receipt, the 3-month-old rats were housed, three rats per cage, in polycarbonate cages measuring $48 \times 27 \times 20 \mathrm{~cm}$ (U.A.R., 91 Epinay-Sur-Orge, France) in a regular environment (temperature $22 \pm 1{ }^{\circ} \mathrm{C}$; humidity $50 \pm 5 \%$ ) with an inverted light-dark cycle (lights on from 20.00 to 08.00 hours). Rats were allowed free access to tap water and their specific diets during the whole experiment. After an acclimatisation period of $7 \mathrm{~d}$ which started at the day of arrival, rats were enumerated by marking the tails using indelible markers and male and female rats were weighed and randomly assigned to one of the four groups (thirty rats per group): male control (Cont-M) group, male Synergy1 (SYN1-M) group, female control (Cont-F) group and female Synergy1 (SYN1-F) group. The present study was performed according to the guidelines of the Association for the Study of Animal Behaviour Ethical Committee for the use of animals in research ${ }^{(21)}$ and the Canadian Council on Animal Care ${ }^{(22,23)}$, and procedures were in agreement with the European Communities Council Directive of 24 November $1986(86 / 609 / \mathrm{EEC})^{(24)}$.

\section{Experimental procedures: animals' stimulation programme}

Throughout the whole experiment, animals were placed once per week for $2 \mathrm{~h}$ in a training environment with large cages, with several floors, provided with scales, tunnels, footbridges and comprising various objects; in dry or water open-fields for encouraging locomotor and exploratory activities and on rotarods for physical locomotor training. Training environments were modified every month to keep environmental stimulation and avoid any habituation of the animals to situations with repetitive spatial configurations. Rats were also allowed to have sexual activity every 6 months, putting the male rats together with 3 -month-old sexually receptive females and females with castrated males for a period of $2 \mathrm{~h}$.

Applying such a training programme during the whole experiment allows rats to age gracefully (harmoniously) and to avoid any disadvantages that occur when breeding in restricted cages due to the lack of social and environmental stimulations which is accompanied by physical, neurological, physiological, psychological and cognitive impairments.

\section{Morphological and biological markers}

Body weight and food intake. All animals in each group were weighed every $15 \mathrm{~d}$. Food intake was evaluated on four successive days every 4-6 weeks.
Body composition. Evaluation of body composition was carried out at 12, 18 and 24 months of age using the non-invasive method of electric conductivity ${ }^{(25,26)}$.

Lipid status and basal glycaemia. At the ages of 12, 18 and 24 months, fasting (12 h fasting period) blood $(300 \mu \mathrm{l})$ samples (twelve rats per group) were taken to assess cholesterol (total cholesterol and HDL), triacylglycerolaemia levels and glycaemia. Cholesterol and triacylglycerolaemia levels were determined using classical laboratory procedures ${ }^{(27)}$.

Basal glycaemia was determined using a reflexion photometer Glucotrend2 (Roche Diagnostics GmbH, Mannheim, Germany) and reactive 'Accu Chek Active Glucose' strips (Roche Diagnostics, Meylan, France). One drop of blood was sampled from the extremity of the tail and the glucose analysis was immediately carried out using the Glucotrend 2 apparatus. A chip of calibration inserted in the apparatus before use and two control solutions of glucose (Accu-Chek Active Control; Roche Diagnostics, Meylan, France) were used.

Lifespan and anatomopathological analyses. At 12, 18 and 24 months of age, three rats per group (one cage randomly chosen, excluding the four cages kept for biological sampling) were anaesthetised with intraperitoneal injections of acepromazine (Calmivet; Vetoquinol, Lure, France) at the dose of $2 \mathrm{mg} / \mathrm{kg}$ and ketamine (Ketamine 1000; Virbac, Carros, France) at the dose of $50 \mathrm{mg} / \mathrm{kg}$. Histological samples were taken: prostate, bladder, seminal vesicles, ovaries, distal part of the colon and brain. Macroscopic and microscopic observations identified the oncological state of the organs. Histological samples were fixed in $10 \%$ formol solution at $\mathrm{pH}$ 7.4 during $12 \mathrm{~h}$ and were then included in paraffin according to Sainte-Marie ${ }^{(28)}$. According to the recommendations of the United Kingdom Coordinating Committee on Cancer Research $^{(29)}$ on ethics, when the body weight (BW) of an animal decreased by more than $25 \%$ or when the animal showed a tumour which size represented more than $10 \%$ of its BW, euthanasia was carried out. The day of euthanasia was considered as the natural day of death of rats to avoid suffering ${ }^{(30)}$. Throughout the experiment, the date of natural death of each rat was noted in order to determine the mean lifespan of each rat.

\section{Statistical analysis}

Student's $t$ test and the Mann-Whitney $U$ test were used to compare data between males and between females of test $v$. control groups. The $\chi^{2}$ test was used to determine lifespan of male and female rats of the four groups. The results are expressed as mean values with their standard errors. Differences are considered to be significant at the level of $P<0 \cdot 05$. All statistical analyses were carried out using the StatView ${ }^{\circledR} 5$ statistical package (SAS Institute, Inc., Cary, NC, USA).

\section{Results}

\section{Morphological and biological markers}

The number of rats per group at each time and for each morphological and biological marker is reported in the figures. At 12, 18 or 24 months, the number of rats could be different between the parameters measured because measurements were made within 1 month, some rats dying during this period; the number of rats 
per group at each time and for each morphological and biological marker is reported in the figures. The biological sampling was done on twelve rats per group and the anatomopathological analyses on three rats per group.

\section{Body-weight evolution}

As shown in Fig. 1, the BW of the SYN1-M group was lower compared with that of the Cont-M group during the whole experiment. Significant differences were observed at 6 $(t=2.94 ; \quad P<0.01), 9 \quad(t=2.61 ; \quad P<0.05), \quad 12 \quad(t=2.15$; $P<0.05), 21 \quad(t=2.66 ; P<0.05)$ and 24 months of age $(t=2.56 ; P<0.05)$ and the BW of the SYN1-M group tended to be lower at $15(t=1.91 ; P<0.10)$ and 18 months of age $(t=1.87 ; P<0 \cdot 10)$.

As shown in Fig. 2, the BW of the SYN1-F group was significantly lower compared with that of the Cont-F group at 6 $(t=2.22 ; P<0.05), 9(t=3.09 ; P<0.01)$ and 12 months of age $(t=2.23 ; P<0.05)$ and tended to be lower at 15 $(t=1.93 ; P<0.10)$ and 21 months of age $(t=1.81 ; P<0 \cdot 10)$.

\section{Food intake}

In male rats, food intake (Table 1) was significantly lower at 18 months of age in the SYN1-M group compared with the Cont-M group $(U=17.5, \quad P<0.05$ for $\mathrm{g} / \mathrm{kg} \mathrm{BW}$ and $U=11.0, P<0.01$ for $\mathrm{kJ} / \mathrm{kg} \mathrm{BW})$. No differences in food intake were observed during the other time points. No differences were observed in food intake in female rats (Table 1), except at 9 months of age when food intake was higher in the SYN1-F group $(U=19.0, P<0.05$ for $\mathrm{g} / \mathrm{kg} \mathrm{BW}$ and $U=28 \cdot 0, P<0 \cdot 10$ for $\mathrm{kJ} / \mathrm{kg} \mathrm{BW})$.

\section{Evolution in body composition}

In male rats, the fat mass composition of the SYN1-M group was not significantly different than that of the Cont-M group even though the results were lower for the SYN1-M rats at 12 months (11.99 (SEM 0.13) \% for SYN1-M (n 12) v. 12.40

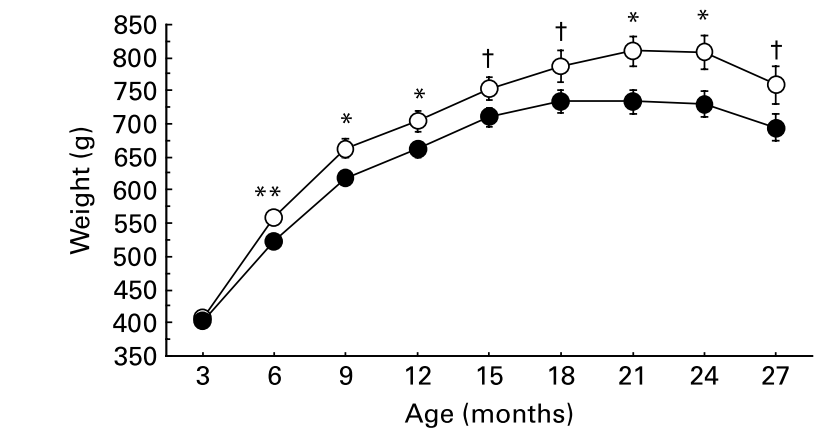

$\begin{array}{llllllllll}\text { Cont-M, n... } & 30 & 30 & 30 & 29 & 26 & 24 & 21 & 16 & 11\end{array}$

$\begin{array}{llllllllll}\text { SYN1-M, n... } & 30 & 30 & 30 & 30 & 27 & 27 & 24 & 21 & 17\end{array}$

Fig. 1. Body-weight evolution in male rats fed a control diet (Cont-M; -O-) or a Synergy1-supplemented diet (SYN1-M; --). Values are means, with standard errors represented by vertical bars. Mean value was significantly different from that of the SYN1-M group: ${ }^{\star} P<0.05$, ${ }^{\star \star} P<0.01$ (Student's $t$ test). † Mean value was marginally significantly different from that of the SYN1-M group $(P<0 \cdot 10$; Student's $t$ test $)$.

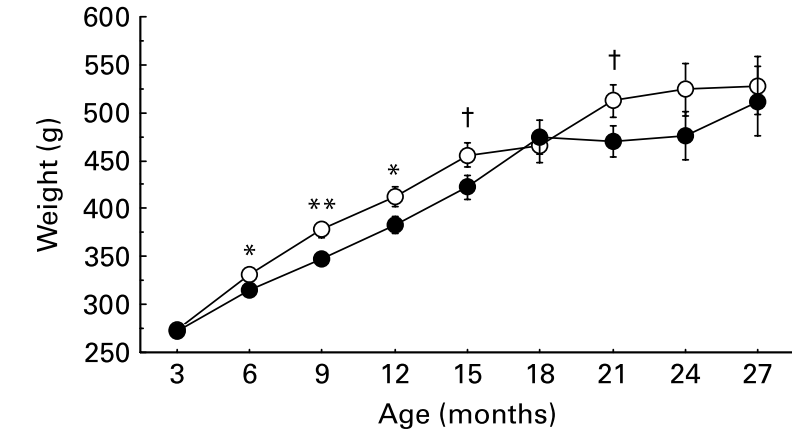

$\begin{array}{llllllllll}\text { Cont-F, } n \ldots & 30 & 30 & 30 & 29 & 26 & 25 & 18 & 9 & 6\end{array}$ $\begin{array}{llllllllll}\text { SYN1-F, } n \ldots & 30 & 30 & 30 & 30 & 27 & 26 & 20 & 12 & 9\end{array}$

Fig. 2. Body-weight evolution in female rats fed a control diet (Cont-F; -O-) or a Synergy1-supplemented diet (SYN1-F; --). Values are means, with standard errors represented by vertical bars. Mean value was significantly different from that of the SYN1-F group: ${ }^{\star} P<0.05$, ${ }^{* *} P<0.01$ (Student's $t$ test). † Mean value was marginally significantly different from that of the SYN1-F group $(P<0 \cdot 10$; Student's $t$ test $)$.

(SEM 0.23) \% for Cont-M (n 12); NS), 18 months (13.28 (SEM 0.35) \% for SYN1-M ( $n$ 11) v. 14.11 (SEM 0.40) \% for Cont-M $(n$ 12); $P<0 \cdot 10)$ and 24 months of age (12.93 (SEM $0.40) \%$ for SYN1-M (n 11) v. 13.88 (SEM 0.48$) \%$ for Cont-M (n 12); $P<0 \cdot 10)$.

Also for the female rats, a similar trend towards a lower fat mass deposition in the SYN1-F group compared with the Cont-F group was observed at 12 months (12.01 (SEM 0.26) \% for SYN1-F $(n$ 12) v. 12.45 (SEM 0.23$) \%$ for Cont-F $(n 11)$; NS), 18 months $(10.82$ (SEM 0.43$) \%$ for SYN1-F $(n 12) v$. 11.77 (SEM 0.37) \% for Cont-F ( $n$ 10); NS) and 24 months of age (10.64 (SEM 0.46$) \%$ for SYN1-F $(n$ 12) v. 12.30 (SEM $0 \cdot 70) \%$ for Cont-F $(n 9) ; P<0 \cdot 10)$.

\section{Triacylglycerolaemia, cholesterol and glucose levels}

As shown in Fig. 3, in the male rats, total cholesterol levels were similar between both groups at 12 months of age and levels were significantly lower in the SYN1-M group after 18 and 24 months of age $(P<0.01$ and $P<0.05$, respectively). With respect to the isolated cholesterol fractions, HDL-cholesterol levels were significantly lower in the SYN1-M than in the Cont-M group $(P<0.05, P<0.01$ and $P<0.01$ at 12,18 and 24 months, respectively). Triacylglycerolaemia levels (Fig. 3) were lower in the SYN1-M group compared with in the Cont-M group during the whole intervention and differences were significant at 18 and 24 months of age $(P<0.05$ and $P<0.005$, respectively).

In the female rats (Fig. 4), levels of triacylglycerolaemia were also significantly lower in the SYN1-F group ( $n$ 12) compared with the Cont-F group $(n 12)$ at 18 months of age $(P<0.05$ for both) whereas no significant differences were found for total or HDL-cholesterol levels.

Fasting glycaemia levels did not differ between groups at any time point.

\section{Anatomopathological analyses}

At 12, 18 and 24 months of age, three rats in each group were euthanised and organs (prostate, bladder, seminal vesicles, 
Table 1. Food intake ( $\mathrm{g} / \mathrm{kg}$ body weight) and energy intake $(\mathrm{kJ} / \mathrm{kg}$ body weight) of rats

(Mean values with their standard errors)

\begin{tabular}{|c|c|c|c|c|c|c|c|c|c|c|c|c|}
\hline \multirow{2}{*}{$\begin{array}{l}\text { Age (months)... } \\
\text { Group }\end{array}$} & \multicolumn{2}{|c|}{9} & \multicolumn{2}{|c|}{12} & \multicolumn{2}{|c|}{15} & \multicolumn{2}{|c|}{18} & \multicolumn{2}{|c|}{21} & \multicolumn{2}{|c|}{24} \\
\hline & Mean & SEM & Mean & SEM & Mean & SEM & Mean & SEM & Mean & SEM & Mean & SEM \\
\hline Food intake & $40 \cdot 2$ & 0.8 & $36 \cdot 8$ & 0.7 & $36 \cdot 2$ & $1 \cdot 1$ & $36 \cdot 4^{*}$ & 0.6 & $37 \cdot 5$ & $5 \cdot 6$ & $36 \cdot 5$ & $3 \cdot 0$ \\
\hline Energy intake & 494.5 & $9 \cdot 2$ & $454 \cdot 0$ & $8 \cdot 4$ & $446 \cdot 9$ & $13 \cdot 0$ & $449 \cdot 8^{\star \star}$ & $7 \cdot 5$ & 461.5 & $69 \cdot 0$ & 448.9 & $37 \cdot 2$ \\
\hline \multicolumn{13}{|l|}{ SYN1-M } \\
\hline Food intake & $41 \cdot 5$ & 0.7 & $36 \cdot 1$ & 0.7 & $38 \cdot 4$ & $0 \cdot 7$ & 33.9 & 0.9 & $33 \cdot 2$ & $1 \cdot 1$ & $33 \cdot 2$ & 1.5 \\
\hline \multicolumn{13}{|l|}{ Cont-F } \\
\hline Food intake & $51 \cdot 0^{\star}$ & $1 \cdot 3$ & $42 \cdot 1$ & $1 \cdot 2$ & $42 \cdot 7$ & 1.9 & $40 \cdot 4$ & $1 \cdot 3$ & $40 \cdot 1$ & 1.9 & $35 \cdot 0$ & $2 \cdot 3$ \\
\hline Energy intake & $628.4 †$ & $16 \cdot 7$ & $516 \cdot 7$ & $15 \cdot 1$ & $527 \cdot 6$ & $23 \cdot 8$ & $497 \cdot 5$ & $16 \cdot 3$ & $495 \cdot 0$ & $23 \cdot 8$ & $417 \cdot 1$ & $28 \cdot 0$ \\
\hline \multicolumn{13}{|l|}{ SYN1-F } \\
\hline Food intake & $55 \cdot 7$ & 1.5 & 44.5 & 1.6 & 45.9 & $1 \cdot 2$ & $40 \cdot 2$ & 1.8 & $41 \cdot 2$ & $2 \cdot 6$ & $35 \cdot 0$ & $2 \cdot 2$ \\
\hline Energy intake & $667 \cdot 8$ & $17 \cdot 6$ & $533 \cdot 0$ & $19 \cdot 2$ & 553.5 & $15 \cdot 1$ & $482 \cdot 8$ & 20.9 & $495 \cdot 4$ & $32 \cdot 6$ & $417 \cdot 1$ & $27 \cdot 6$ \\
\hline
\end{tabular}

Cont-M, male control; SYN1-M, male Synergy1; Cont-F, female control; SYN1-F, female Synergy1.

${ }^{*}$ Mean food intake was significantly different from that of the rats of the same age and sex fed the Synergy 1 -supplemented diet $(P<0.05 ;$ Mann-Whitney $U$ test).

${ }^{* *}$ Mean energy intake was significantly different from that of the rats of the same age and sex fed the Synergy 1 -supplemented diet $(P<0.01$; Mann-Whitney $U$ test).

† Mean energy intake was marginally significantly different from that of the rats of the same age and sex fed the Synergy 1 -supplemented diet $(P<0 \cdot 10$; Mann-Whitney $U$ test)

ovary, distal part of the colon and brain) were analysed for abnormalities. No specific differences in anatomopathological lesions were detected between the groups. Normally occurring lesions due to the ageing process such as acute prostatitis and mammary adenofribroma were found among the groups.

\section{Physical appearance and lifespan}

No significant differences were observed between the causes of death of the rats fed the control or Synergy 1 diet. Some of them were found dead in the cage; mostly males that died of both groups were weak and they had lost $25 \%$ of their highest

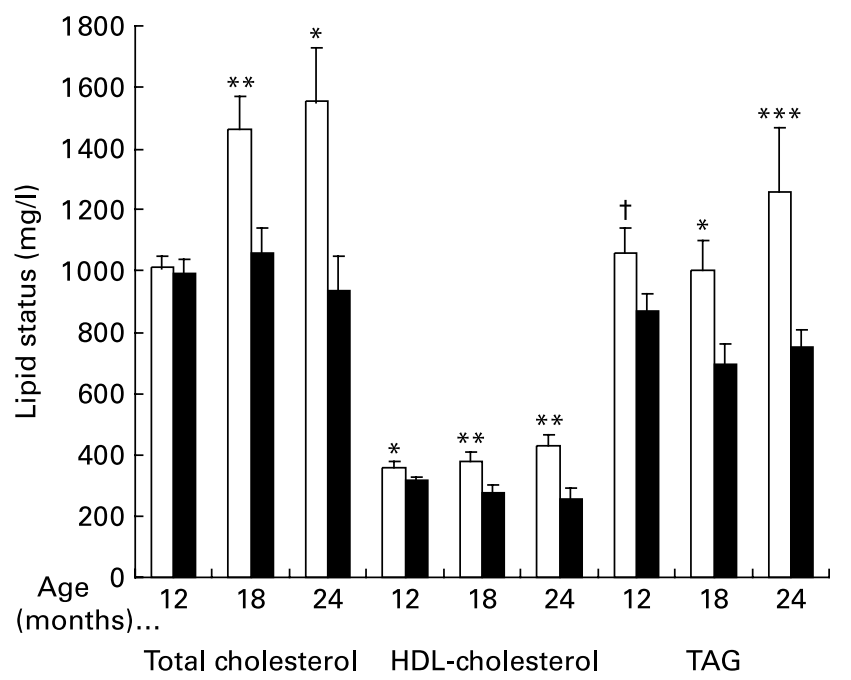

Fig. 3. Lipid status in male rats fed a control diet (Cont-M; $\square$ ) or a Synergy1-supplemented diet (SYN1-M; $\mathbf{\square})$. At 12 and 18 months there were twelve rats in each group; at 24 months there were six rats in the Cont-M group and eight rats in the SYN1-M group. Values are means, with standard errors represented by vertical bars. Mean value was significantly different from that of the SYN1-M group: ${ }^{\star} P<0.05,{ }^{* \star} P<0.01$, ${ }^{\star * \star} P<0.005$ (Student's $t$ test or Mann-Whitney $U$ test). † Mean value was marginally significantly different from that of the SYN1-M group $(P<0 \cdot 10$; Mann-Whitney $U$ test). weight. In the Cont-F and SYN1-F groups, females developed mammary fibromas and when the volume of the mass became superior to $10 \%$ of the weight of the rat, they were euthanised. Only one difference was observed: the control rats died earlier than the Synergy1 rats but of the same causes.

Rats of the SYN1-M group showed a fur well-groomed and were in a better condition compared with rats of the Cont-M group at 24 months of age (Fig. 5); they were still interested in their environment. In their home cage, rats of the SYN1-M group continued to be interested by the activity in the animal room (entrance of animal-care individuals, food distribution, etc); rats came in front of their cage in a rearing position and they played with their cage mates. In the stimulation programme they showed curiosity and more activity than the Cont-M group. No difference was observed in the appearance of the Cont-F and SYN-F groups.

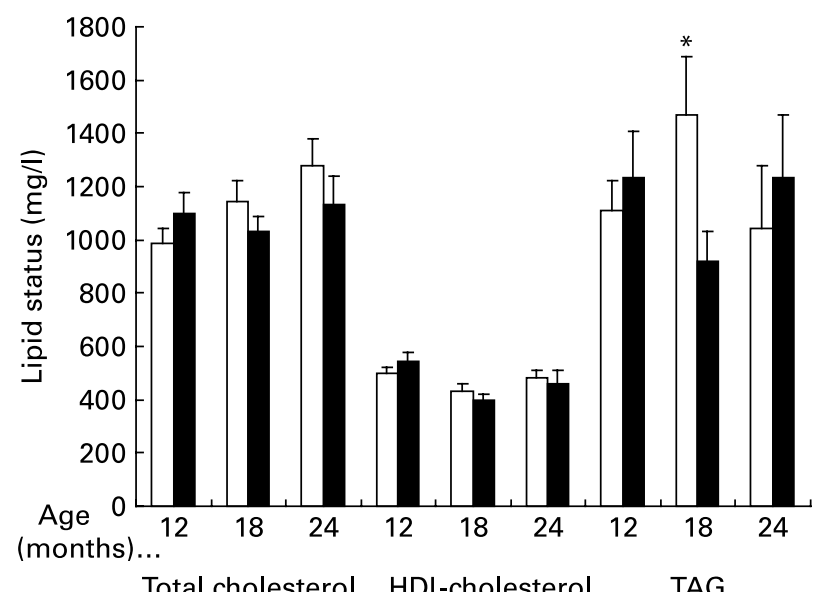

Fig. 4. Lipid status in the female rats fed a control diet (Cont-F; $\square$ ) or a Synergy1-supplemented diet (SYN1-F; $\mathbf{\square})$. At 12 and 18 months there were twelve rats in each group; at 24 months there were three rats in the Cont-F group and six rats in the SYN1-F group. Values are means, with standard errors represented by vertical bars. ${ }^{*}$ Mean value was significantly different from that of the SYN1-F group ( $P<0.05$; Student's $t$ test). 
(a)

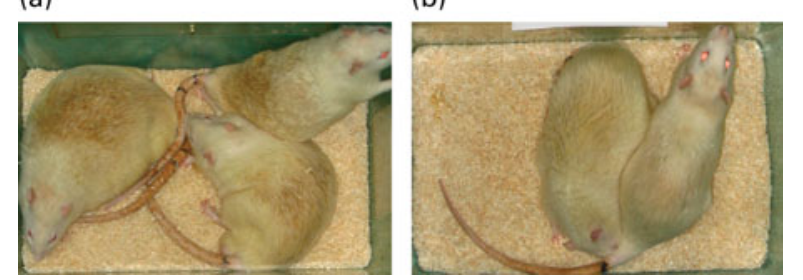

Fig. 5. Appearance of the male rats fed a control diet (a) or a Synergy1-supplemented diet (b) at 24 months of age.

To determine the lifespan of male and female rats, twentyone rats in each group were followed. As shown in Fig. 6, the survival rate of rats of the SYN1-M group was significantly higher than that of the rats of the Cont-M group at the age of 18 months $(100.0 \%$ in SYN1-M v. $76.2 \%$ in Cont-M, $\left.\chi^{2}=20.06, P<0.001\right)$ and 24 months $(81.0 \%$ in SYN1-M v. $52.4 \%$ in Cont-M; $\left.\chi^{2}=14.36 ; P<0.001\right)$. At 24 months of age, the SYN1-M group was composed of $35.3 \%$ more rats than the Cont-M group.

For the female rats, as shown in Fig. 7, the survival rate in the SYN1-F group tended to be higher than in the Cont-F group at 12 months of age $(100.0 \%$ in SYN1-F $v .95 .2 \%$ in Cont-F; $P<0.06)$ and differences were significant at 24 months of age $(42.9 \%$ in SYN1-F v. $28.6 \%$ in Cont-F; $\left.\chi^{2}=4.28 ; P<0.05\right)$. At 24 months of age, the SYN1-F group was composed of $33.3 \%$ more rats than the Cont-F group.

\section{Discussion}

The study was designed to determine the effects of lifelong supplementation with an oligofructose-enriched inulin (Synergy1) in rats on the onset of age-related physiological and morphological changes (BW, fat mass, blood levels of cholesterol, TAG and glucose) and the prolongation of life. With ageing, the increase in fat-mass storage and excess weight gain accounts for many of the ageing-associated morbidities and

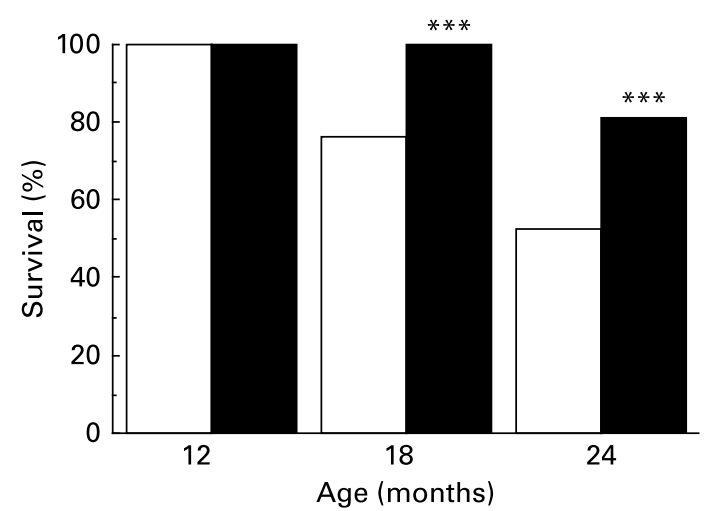

Cont-M, $n$.

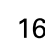

11

SYN1-M n...

21

21

17

Fig. 6. Survival rate of male rats fed a control diet (Cont-M; $\square$ ) or a Synergy1-supplemented diet (SYN1-M; $\mathbf{\square})$. ${ }^{\star \star \star}$ Survival rate was significantly different from that of the Cont-M group $\left(P<0.001 ; \chi^{2}\right.$ test).

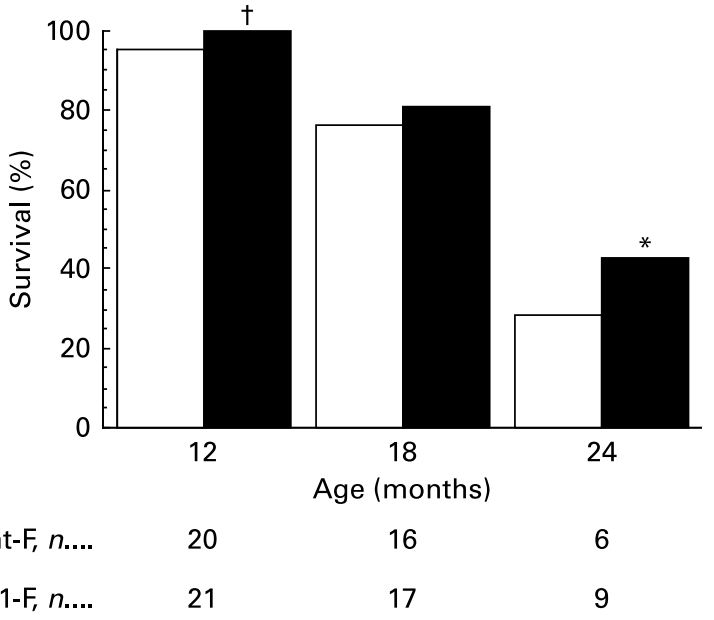

Fig. 7. Survival rate of female rats fed a control diet (Cont-F; $\square$ ) or a Synergy1-supplemented diet (SYN1-F; $\square$ ). * Survival rate was significantly different from that of the Cont-F group $\left(P<0.05 ; \chi^{2}\right.$ test). †Survival rate was marginally significantly different from that of the Cont $\mathrm{F}$ group $(P<0 \cdot 10$; $\chi^{2}$ test).

mortality. Given the increased prevalence of overweight during adolescence and adulthood, strategies to modulate BW during ageing are important in the prevention of disease and more particularly chronic diseases associated with excess fat storage. The results of the present study show that lifelong administration of Synergy1 to adult rats limits excess BW gain over the lifespan. These results are consistent with previously obtained findings that showed a decrease in BW and fat mass (epididymal fat mass) in rats fed a diet enriched with oligofructose ${ }^{(30,31)}$. In the present study, Synergy1-supplemented rats (particularly males) had lower cholesterol and TAG levels during the whole intervention. This is in accordance with the findings of Fiordaliso et al. ${ }^{(14)}$, who demonstrated reductions in serum TAG in rats when fed fructo-oligosaccharides. In the same way, it was shown that male rats fed a high-fat diet supplemented with inulin or oligofructose $(10 \%)$ had significantly lower serum TAG and phospholipid levels, reduced postprandial triacylglycerolaemia (by $50 \%$ ) and lower cholesterolaemia ${ }^{(13)}$. Kok et al. ${ }^{(32)}$ also demonstrated that rats fed Synergy1 had lower serum TAG levels through to a reduction in the de novo fatty acid synthesis in the liver. The authors also showed that oligofructose added to a high-fat diet protected rats against an increase of free cholesterol serum level induced by the high-fat diet. In the latter study, oligofructose also decreased serum TAG by enhancing TAG-rich lipoprotein catabolism ${ }^{(33)}$. Another study in hamsters (fed with high-fat or cholesterol-rich diets) found that inulin lowered blood lipids and that this was due to several mechanisms, including altered hepatic TAG synthesis and VLDL secretion and impaired reabsorption of circulating bile acids $^{(34)}$. Daubioul et al. ${ }^{(30,35)}$ showed that growing obese Zucker rats fed with an oligofructose-enriched diet had less BW gain and lower TAG accumulation in the liver. The high propionate concentrations in the portal vein ( $v$. control rats) may explain the lipid-modulating actions of inulin and oligofructose, since propionate is well known to be involved in lipid metabolism. Along with the hypotriacylglycerolaemic 
effect of inulin and oligofructose, Busserolles et al. ${ }^{(36)}$ found a protective effect of oligofructose against oxidation induced by a high-fructose diet. In the latter study, oligofructose supplementation increased the vitamin E:TAG ratio, lowered thiobarbituric acid-reactive substances and reduced heart tissue susceptibility to peroxidation. Additionally, in male apo E-deficient mice, oligofructose-enriched inulin (Synergy1) supplementation lowered atherosclerotic-lesioned areas by $25 \%$ and this was related to the changes in lipid metabolism ${ }^{(37)}$. Also, other studies showed the cholesterol-lowering potential of inulin in mice with spontaneous hypercholesterolaemia ${ }^{(38)}$ and in $\mathrm{Balb} / \mathrm{c}$ mice $\mathrm{e}^{(39)}$. It appears that there is not a single biochemical locus through which prebiotics modulate serum, hepatic and whole-body lipid content in animals. The effects observed depend on the pathophysiological and nutritional conditions ${ }^{(40)}$.

Also, in humans with modest hyperlipidaemia, inulin supplementation to the diet significantly lowered total cholesterol and LDL concentrations ( $v$. placebo phase), but no effects on HDL-cholesterol or serum TAG concentrations were seen ${ }^{(15)}$. Canzi et al. ${ }^{(41)}$ observed significant lower TAG and cholesterol concentrations in young male volunteers consuming $9 \mathrm{~g}$ inulin per $\mathrm{d}$. In healthy young men, $18 \%$ of inulin in a cereal breakfast for 4 weeks had no effects on BW, faecal and bile acid output or faecal SCFA, whereas plasma total cholesterol and TAG decreased. Changes in blood lipids were negatively correlated with bifidobacteria counts and positively with secondary bile acid excretion. Also, Brighenti et al. ${ }^{(42)}$ concluded that inulin has lipid-lowering potential, probably mediated by mechanisms related to its colonic fermentation. The addition of $10 \mathrm{~g}$ inulin to the diet of middle-aged men and women for 8 weeks resulted in lower plasma TAG levels, particularly in subjects in whom fasting TAG levels were greater than $1.5 \mathrm{mmol} / \mathrm{l}^{(43)}$. The risk factors for atherosclerosis were also reduced by inulin supplementation in the study of Letexier et al. ${ }^{(44)}$ in which men ingested a highcarbohydrate, low-fat diet supplemented with $10 \mathrm{~g}$ inulin per $\mathrm{d}$ for 3 weeks. Inulin supplementation led to a lower plasma TAG concentration and hepatic lipogenesis ${ }^{(44)}$. Oligosaccharides and inulin are almost completely fermented in the human colon, producing SCFA (acetate, propionate, butyrate) ${ }^{(45)}$ Acetate traverses the liver and enters the peripheral circulation, propionate is extracted by the liver and affects lipid metabolism $^{(46)}$ and butyrate leaves the colon for extraction by the liver ${ }^{(45)}$. An in vitro fermentation of inulin by bacteria growing in the human large intestine showed an acetate: propionate: butyrate ratio of $72: 19: 8^{(47)}$. Because soluble dietary fibres such as oligofructose or inulin are extensively fermented in the colon, they also have a potential to increase the bifidobacteria counts of the colon. This elevation in bifidobacteria offers health benefits independent of those normally attributed to fibre-rich foods. Inclusion of soluble dietary fibres in the diet offers benefits not only to the heart, but also to overall health ${ }^{(48)}$.

In the present study, fasting glycaemia was not affected by inulin supplementation, most probably because the glycaemia of the rats was within the normal range. In the studies of Cani et $a .^{(31)}$ and Delzenne et al. ${ }^{(49)}$ oligofructose was found to restore normal glycaemia in diabetic-induced rats.

Interestingly, the present study demonstrated for the first time increased survival rates of both male and female rats after lifelong supplementation with Synergy1. However, the observed anatomopathological lesions were not affected by the type of feeding, and if any abnormalities were presented these were related to the ageing process. The mechanisms underlying this prolongation of life with Synergy1 supplementation remain unclear, but it might be assumed that this is related to the beneficial changes in biomarkers observed in the present study. Inulin-type fructans stimulate health-promoting bacteria in the large intestine, thereby improving digestive health which is vital to maintain overall health and wellbeing. The use of Synergy1 in the diet offers several advantages compared with energy-restricted diets that permit the extension of survival rate: energy-restricted diets have been tested in rodents, usually in post-weaning animals during all their life, and a study in mice showed that mice were hungry during the whole experimental period ${ }^{(50)}$. These conditions are unacceptable and unfeasible in humans. Inulin and oligofructoses are already common in human food (cereal bars, bread, chocolate, cheese, sugar, pasta, noodles, frozen desserts, etc) and could be eaten each day without chance of distaste. In rodents, a 40-45\% energy-restricted diet $^{(51)}$ taken during all life or a $10 \%$ Synergy 1 diet, without hunger and with good health and life pleasure, involved a similar extension of life of $30-35 \%$.

To conclude, the present study showed that lifelong supplementation with Synergy1 limited BW and fat-mass gains and beneficially modulated lipid metabolism during ageing, and additionally increased lifespan in rats. Further studies are needed to investigate the mechanisms by which Synergy1 increases lifespan and whether such prevention of age-related dysfunctions by administration of Synergy 1 can be observed in humans as well.

\section{Acknowledgements}

All the authors of this article attest that there was no potential conflict of interest that could have influenced the present study. No author's institution has contracts relating to this research through which it or any other organisation may stand to gain financially now or in the future. No other agreements of authors or their institutions could be seen as having a financial interest in the study.

Financial support related to the paper was provided by BENEO-Orafti.

All authors have reviewed the contents of the paper, approve of its contents and validate the accuracy of the data.

\section{References}

1. Van Loo J, Coussement P, De Leenheer L, Hoebregs H \& Smits $\mathrm{G}$ (1995) On the presence of inulin and oligofructose as natural ingredients in Western diet. CRC Crit Rev Food Sci Nutr 35, 525-552.

2. Roberfroid MB (1999) Concepts in functional foods: the case of inulin and oligofructose. J Nutr 129, S1398-S1401.

3. Coudray C, Bellanger J, Castiglia-Delavaud C, Remesy C, Vermorel M \& Rayssignuir Y (1997) Effects of soluble or partly soluble dietary fibres supplementation on absorption and balance of calcium, magnesium, iron and zinc in healthy young men. Eur J Clin Nutr 51, 375-380.

4. Gibson GR \& Roberfroid MB (1995) Dietary modulation of the human colonic microbiota: introducing the concept of prebiotics. J Nutr 125, 1401-1412. 
5. Rao A (2001) The prebiotic properties of oligofructose at low intake levels. Nutr Res 21, 843-848.

6. Tuohy KM, Finlay RK, Wynne AG \& Gibson GR (2001) A human volunteer study on the prebiotic effects of HP-inulin faecal bacteria enumerated using fluorescent in situ hybridisation (FISH). Anaerobe 7, 113-118.

7. Delzenne N, Aertssens J, Verplaetse H, Roccaro M \& Roberfroid M (1995) Effects of fermentation fructooligosaccharides on mineral, nitrogen and energy digestive balance in the rat. Life Sci 57, 1579-1587.

8. Roberfroid MB, Cumps J \& Devogelaer JP (2002) Dietary chicory inulin increases whole-body bone mineral density in growing male rats. $J$ Nutr 132, 3599-3602.

9. Griffin IJ, Davila PM \& Abrams SA (2002) Non-digestible oligosaccharides and calcium absorption in girls with adequate calcium intakes. Br J Nutr 87, Suppl. 2, S187-S191.

10. Griffin IJ, Mushi A, Hilmers DC, Allen LH, Hicks PD \& Abrams SA (2003) Enriched chicory inulin increases calcium absorption mainly in girls with lower calcium absorption. Nutr Res 23, 901-903.

11. Abrams SA, Griffin IJ, Hawthorne KM, Liang L, Gunn SK, Darlington G \& Ellis KJ (2005) A combination of prebiotic shortand long-chain inulin-type fructans enhances calcium absorption and bone mineralization in young adolescents. Am J Clin Nutr 82, 471-476.

12. Delzenne N \& Kok NN (1998) Effect of non-digestible fermentable carbohydrates on hepatic fatty acid metabolism. Biochem Soc Trans 26, 228-230.

13. Delzenne NM, Daubioul C, Neyrinck A, Lasa M \& Taper HS (2002) Inulin and oligofructose modulate lipid metabolism in animals: review of biochemical events and future prospects. Br J Nutr 87, Suppl. 2, S255-S259.

14. Fiordaliso MF, Kok N, Desager JP, Goethals F, Deboyser D, Roberfroid M \& Delzenne N (1995) Dietary oligofructose lowers triglycerides, phospholipids and cholesterol in serum and very low density lipoproteins of rats. Lipids 30, 163-167.

15. Davidson MH, Synecki C, Maki KC \& Drennan KB (1998) Effects of dietary inulin in serum lipids in men and women with hypercholesterolemia. Nutr Res 3, 503-517.

16. Pereira DI \& Gibson GR (2002) Effects of consumption of prebiotics on serum lipid levels in humans. Crit Rev Biochem Mol Biol 37, 259-281.

17. Watzl B, Girrbach S \& Roller M (2005) Inulin, oligofrucrose and immunomodulation. Br J Nutr 93, S49-S55.

18. Roller M, Pietro Femia A, Caderni G, Rechkemmer G \& Watzl B (2004) Intestinal immunity of rats with colon cancer is modulated by oligofructose-enriched inulin combined with Lactobacillus rhamnosus and Bifidobacterium lactis. Br J Nutr 92, 931-938.

19. Taper HS \& Roberfroid MB (2005) Possible adjuvant cancer therapy by two prebiotic-inulin or fructose. In Vivo 19, 201-204.

20. Rafter J, Bennett M, Caderni G, et al. (2007) Dietary synbiotics reduce cancer risk factors in polypectomized and colon cancer patients. Am J Clin Nutr 85, 488-496.

21. Animal Behavior Society \& Association for the Study of Animal Behaviour (2006) Guidelines for the treatment of animals in behavioural research and teaching. Anim Behav 71, 245-254.

22. Olfert ED, Cross BM \& McWilliam AA (1993) Guide to the Care and Use of Experimental Animals, vol. 1, 2nd ed. Ottawa, ON: Canadian Council of Animal Care.

23. Olfert ED, Cross BM \& McWilliam AA (1984) Guide to the Care and Use of Experimental Animals, vol. 2. Ottawa, ON: Canadian Council of Animal Care.

24. European Union (1986) Council Directive 86/609/EEC of 24 November 1986 on the approximation of laws, regulations and administrative provisions of the Member States regarding the protection of animals used for experimental and other scientific purposes. http://eur-lex.europa.eu/LexUriServ/LexUri Serv.do?uri = CELEX:31986L0609:EN:HTML

25. Cunningham JJ, Molnar JA, Meara PA \& Bode HH (1986) In vivo total body electrical conductivity following perturbations of body fluid compartments in rats. Metabolism 6, $572-575$.

26. Unangst ET \& Merkley LA (2002) The effects of lipid location on non-invasive estimates of body composition using EMSCAN technology. J Exp Biol 205, 3101-3105.

27. Anonymous (1989) Consensus français sur le cholesterol et les dyslipémies (The French consensus on cholesterol and dyslipoproteinemias. Administration Council of ARCOL). Rev Prat 39, 972-974.

28. Sainte-Marie G (1962) A paraffin embedding technique for studies employing immuno-fluorescence. J Histochem Cytochem 10, 250-256.

29. Anonymous (1998) United Kingdom co-ordinating committee on cancer research (UKCCCR) guidelines for the welfare of animals in experimental neoplasia (second edition). Br J Cancer 77, $1-10$.

30. Daubioul CA, Taper HS, De Wispelaere LD \& Delzenne NM (2000) Dietary oligofructose lessens hepatic steatosis, but does not prevent hypertriglyceridemia in obese Zucker rats. $J$ Nutr 130, 1314-1319.

31. Cani PD, Neyrinck AM, Maton N \& Delzenne NM (2005) Oligofructose promotes satiety in rats fed a high-fat diet: involvement of glucagon-like peptide-1. Obes Res 13, 1000-1007.

32. Kok N, Roberfroid M, Robert A \& Delzenne N (1996) Involvement of lipogenesis in the lower VLDL secretion induced by oligofructose in rats. Br J Nutr 76, 881-890.

33. Kok NN, Taper HS \& Delzenne NM (1998) Oligofructose modulates lipid metabolism alterations induced by a fat-rich diet in rats. J Appl Toxicol 18, 47-53.

34. Trautwein EA, Rieckhoff D \& Erbersdobler HF (1998) Dietary inulin lowers plasma cholesterol and triacylglycerol and alters biliary bile acid profile in hamsters. J Nutr 128, 1937-1943.

35. Daubioul C, Rousseau N, Demeure R, Gallez B, Taper H, Declerck B \& Delzenne N (2002) Dietary fructans, but not cellulose, decrease triglyceride accumulation in the liver of obese Zucker falfa rats. J Nutr 132, 967-973.

36. Busserolles J, Gueux E, Rock E, Demigné C, Mazur A \& Rayssiguier Y (2003) Oligofructose protects against the hypertriglyceridemic and pro-oxidative effects of a high fructose diet in rats. J Nutr 133, 1903-1908.

37. Rault-Nania MH, Gueux E, Demougeot C, Demigne C, Rock E \& Mazur A (2006) Inulin attenuates atherosclerosis in apolipoprotein E-deficient mice. Br J Nutr 96, 840-844.

38. Mortensen A, Poulsen M \& Frandsen H (2002) Effect of a longchained fructan Raftiline HP on blood lipids and spontaneous atherosclerosis in low density receptor knockout mice. Nutr Res 22, 473-480.

39. Chen H-L, Hsiang Y-Y, Wu W-T \& Lin M-S (2005) Hypolipidemic effects of inulin and synthetic oligofructose in Balb/c mice. Nutr Sci 30, 99-107.

40. Delzenne NM \& Williams C (2002) Prebiotics and lipid metabolism. Curr Opin Lipidol 13, 61-67.

41. Canzi E, Brighenti F, Casiraghi MC, Del Puppo E \& Ferrari A (1995) Prolonged consumption of inulin in ready to eat breakfast cereals: effects in intestinal ecosystem, bowel habits and lipid metabolism. In COST 92, Workshop. Dietary Fiber and Fermentation in the Colon, Helsinki, Finland, 15:17/04, pp. 280-284. Luxembourg: Office for Official Publications of the European Communities.

42. Brighenti F, Casiraghi MC, Canzi E \& Ferrari A (1999) Effect of consumption of a ready-to-eat breakfast cereal containing 
inulin on the intestinal milieu and blood lipids in healthy male volunteers. Eur J Clin Nutr 53, 726-733.

43. Jackson KG, Taylor GR, Clohessy AM \& Williams CM (1999) The effect of the daily intake of inulin on fasting lipid, insulin and glucose concentrations in middle-aged men and women. Br J Nutr 82, 23-30.

44. Letexier D, Diraison F \& Beylot M (2003) Addition of inulin to a moderately high-carbohydrate diet reduces hepatic lipogenesis and plasma triacylglycerol concentrations in humans. Am J Clin Nutr 77, 559-564.

45. Pomare EW, Branch WJ \& Cummings JH (1985) Carbohydrate fermentation in human colon and its relationship to acetate concentrations in venous blood. J Clin Invest 75, 1448-1454.

46. Bridges SR, Anderson JW, Deakins DA \& Wood CA (1992) Oat bran increases serum acetate of hypercholesterolemic men. Am J Clin Nutr 56, 455-459.
47. Wang X \& Gibson GR (1993) Effects of the in vitro fermentation of oligofructose and inulin by bacteria growing in the human large intestine. J Appl Bacteriol 75, 373-380.

48. Anderson JW \& Hanna TJ (1999) Impact of nondigestible carbohydrates on serum lipoproteins and risk for cardiovascular disease. J Nutr 129, S1457-S1466.

49. Delzenne NM, Cani PD, Daubioul C \& Neyrinck AM (2005) Impact of inulin and oligofructose on gastrointestinal peptides. Br J Nutr 93, Suppl. 1, S157-S162.

50. Speakman J \& Hambly C (2007) Starving for life: what animal studies can and cannot tell us about the use of caloric restriction to prolong human lifespan. J Nutr 137, 1078-1086.

51. Sohal RS, Ku HH, Agarwal S, Forster MJ \& Lal H (1994) Oxidative damage, mitochondrial oxidant generation and antioxidant defences during aging and in response to food restriction in the mouse. Mech Ageing Dev 74, 121-123. 